\title{
Total Arterial Revascularization and The Future of Long Saphenous Vein
}

\author{
Amer Harky*1 and Christiana Bithas $^{2}$ \\ ${ }^{1}$ Department of Cardiothoracic Surgery, Liverpool Heart and Chest, UK \\ ${ }^{2}$ School of Medicine, University of Liverpool, UK
}

*Corresponding author: Amer Harky, Department of Cardiothoracic Surgery, Liverpool Heart and Chest Hospital, Liverpool, UK

\section{ARTICLE INFO}

Received: March 01, 2019

Published: March 14, 2019

Citation: Amer Harky, Christiana Bithas. Total Arterial Revascularization and The Future of Long Saphenous Vein. Biomed J Sci \& Tech Res 15(5)2019. BJSTR. MS.ID.002776.

\begin{abstract}
Total arterial revascularization during coronary artery bypass surgery has proven its superiority over vein graft conduits in both long-term patency and lower conduit associated complications, especially in the young population. Yet, the use of long saphenous vein as a reliable conduit is still in practice, especially in cohorts where a systemic vascular disease exists and there is risk of involvement of internal thoracic and radial arteries in such pathology. With modern day practice and the increasing evidence of arterial conduit supremacy over the vein grafting, the fate of such vein conduit utilization comes into question. With modern day practice and the increasing evidence of arterial conduit supremacy over the vein grafting, the fate of such vein conduit utilization comes into question. This brief review focuses on current evidence behind total arterial revascularization and use of long saphenous vein as a reliable conduit for coronary revascularization.
\end{abstract}

Abbreviations: CABG: Coronary Artery Bypass Grafting; LSV: Long Saphenous Vein; LITA: Left Internal Thoracic Artery; RITA: Right Internal Thoracic Artery; BITA: Bilateral Internal Thoracic Arteries; ART: Arterial Revascularization Trial; RA: Radial Artery

\section{Introduction}

Coronary artery bypass grafting (CABG) is one of the most common cardiac surgery procedures being performed nowadays [1]. The key for a long-term successful outcome is grafting the diseased coronary vessels with appropriate conduits to provide the longest possible patency rate. Currently, the choices of conduits are in the forms of either arterial type and this includes left or right internal thoracic artery, radial artery or venous conduit as in using the long saphenous vein (LSV), [2]. The arterial conduits can be used either alone such as total arterial revascularization or combined with vein grafts. Up to today, there is no strict guidelines on using either conduits during CABG, and the choice of such remains multifactorial including surgeon preference [2]. The use of left internal thoracic artery (LITA) as first conduit is associated with excellent long-term outcomes and it remains the gold standard conduit of choice, while the choice of second conduit types remains debatable [3]. Several studies have been published comparing the use of multiple arterial conduits over the use of LSV and the consensus is that arterial grafts have higher patency rates over the LSV graft [4]. Nevertheless, the long-term outcome in choosing which arterial conduit is not consistent and yet not confirming the superiority of either conduits beyond the use of LITA and therefore, the use of LSV remains as one of the most common conduits being utilized in CABG [5].

\section{Total Arterial Revascularization}

The most common arterial graft used for total arterial revascularization is LITA, the other options includes right internal thoracic artery (RITA), radial artery and, less often these days, the right gastroepiploic artery [2]. The use of bilateral internal thoracic arteries (BITA) and often the radial artery as sequential graft has been also described in literature as a no touch technique which doesn't involve proximal anastomosis to the ascending aorta [6]. This technique is particularly useful in patients with porcelain aorta or severely calcified ascending aorta and no chance of aortic cannulation and use of cardiopulmonary bypass; therefore, an off-pump CABG is performed in such cases [7]. The success of using LITA is in its long- 
term patency of more than $90 \%$ at 10 years of follow-up, while the LSV has a reported patency rate of only $25 \%$ or less at 10 years [8]. Additionally, the internal thoracic artery is lacking much of muscular layers and is rich in elastic laminae which not only provides a relative degree against vasospasm but also helps in producing nitric oxide and other anti-inflammatory agents [9].

Just a month ago, the 10 year follow up from arterial revascularization trial (ART) have reported a no superiority of BITA over LITA use in patients undergoing CABG and this questions all the previous studies that have reported a significant benefit of using RITA as a second arterial conduit, whether as a free graft or in a sequential approach [10]. Prior to the results from ART, several systematic review and meta-analyses have found the use of BITA to be associated with long term benefits such as reduction in mortality rate $[11,12]$. The meta-analysis by Weiss et al. that analysed 79,000 patients that underwent CABG using LITA vs BITA, reported a significant improvement in long-term mortality rates in patients that received BITA (HR: 0.78; 95\% confidence interval [CI]: 0.72 to $0.84 ; \mathrm{p}<0.00001)$, [11]. Those results were similarly reported in the meta-analysis by Yi et al. [12] which favored the used of BITA, their data even included the mean follow up of over 9 years. However, those results have been scrutinized by the output from the ART trial and didn't demonstrate any superiority of BITA over LITA and therefore, the debate carries on for a potential larger trial with a longer follow up beyond 10 years. Another arterial conduit that is commonly used in CABG is the radial artery (RA).

It is widely reported that RA have significant higher patency rates over the use of LSV [13]. The literature is dominant with randomized controlled trials and meta-analyses comparing the use of RA vs LSV as second conduit to LITA [14-16]. The latest published large study is from Radial Artery Database International Alliance (RADIAL) by Gaudino et al. [13], in which they compared the outcomes of 1036 patients (534 patients with RA and 502 with LSV). The authors reported their outcomes with a mean follow-up of $60 \pm 30$ months; the noted a lower incidence of adverse cardiac events in patients that received RA versus LSV grafts (HR, 0.67; 95\% CI, 0.49 - 0.90; $\mathrm{P}=0.01$ ). Additionally, the use of RA was associated with higher patency rates ( $\mathrm{HR}, 0.44 ; 95 \% \mathrm{CI}, 0.28$ - 0.70; $\mathrm{P}<0.001$ ); there was also a lower rate of repeat revascularization (HR, 0.50; 95\% CI, 0.40 - 0.63; P<0.001). However, the overall mortality rates didn't differ between both cohorts (HR, 0.90; 95\% CI, 0.59 - 1.41; $\mathrm{P}=0.68$ ). Those outcomes were also emphasized by earlier larger systematic reviews and meta-analyses that reported higher patency rates and lower cardiovascular events rate in patients receiving RA as second conduit [17].

However, the use of RA is not always possible as it has its own limitations, such as involvement in systemic vascular diseases, or patients who have a positive Allen's test Allen's test is positive or have doppler scan confirming inadequate flow of blood through the ulnar artery in the same hand and thus careful consideration for the use of RA should be thought prior to routine harvesting. Finally, the worry in using BITA over LITA is the reported higher rate of deep sternal wound (SWI) infection and mediastinitis $[3,10]$. This complication is a serious surgical site infection and can be catastrophic if not recognized and managed appropriately. The increased rate of sternal wound infection is noted especially in patients with diabetes or pulmonary diseases; this was clearly reported in ART trial and several other systematic review and metaanalyses $[10,18,19]$. Yet, this can be reduced to the lowest possible rate by careful patient selection and the technique of harvesting the ITA. Nevertheless, the choice of RA is free from such serious complication and it is very safe to be used as second arterial graft to LITA. In two separate propensity-matched comparisons of using RA or RITA as second conduit, RA showed superiority in terms of lower rates of SWI's. In addition to lack of connection of RA to SWI; RA has shown to be protective against graft occlusion in long term.

\section{Long Saphenous Vein Use}

Yes, the current evidence suggests the use of total arterial revascularization as it provides a better long-term outcomes and patency rates, and this is very important especially in young patients with multiple coronary artery diseases. However, as we explained earlier, the choice of second arterial conduit remains debatable and there is no clear consensus of which artery to use in addition to LITA. BITA has been proven of not being superior to LITA alone, RA has its own limitations and it is not always feasible to harvest. Gaudino et al. [2] proposed a legitimate algorithm to choose the type of conduit based on location of the diseased coronary arteries. In the essence, if the targeted vessel narrowing is $<70 \%$ or there is inferior wall stenosis of 70-90\%, then LSV graft would be a reliable and good conduit choice. LSV conduit is not associated with the risks that arterial grafts could pose, such as SWI, involvement in systemic vascular disease or being prone to severe vasospasm. Additionally, it is technically easy to harvest this conduit and several techniques are currently in place to harvest LSV ranging from open to endoscopic techniques with satisfactory length to be used for the bypass grafting [20]. Furthermore, it has enough length and it lacks atheroma's that otherwise can exist in arterial conduits. Yet, the key draw back in using the LSV is the reduced long-term patency rate when compared to arterial conduits.

\section{Conclusion}

Total arterial revascularization should be considered for coronary artery bypass grafting where feasible and appropriate conduits can be harvested. Long saphenous vein remains a reliable and alternative of conduit, especially in elderly patients or patients with systemic vascular disease.

\section{References}

1. Buxton BF, Hayward PAR, Newcomb AE, Moten S, Gordon I, et al. (2009) Choice of conduits for coronary artery bypass grafting: craft or science? Eur J Cardio-Thoracic Surg 35(4): 658-670. 
2. Gaudino M, Taggart D, Suma H, Puskas JD, Crea F, Massetti M (2015) The Choice of Conduits in Coronary Artery Bypass Surgery. J Am Coll Cardiol 66(15): 1729-1737.

3. Martínez González B, Reyes Hernández CG, Quiroga Garza A, Rodríguez VE, Esparza Hernández CN, et al. (2017) Conduits Used in Coronary Artery Bypass Grafting: A Review of Morphological Studies. Ann Thorac Cardiovasc Surg 23(2): 55-65.

4. Gaudino M, Benedetto U, Fremes S, Biondi Zoccai G, Puskas JD, et al. (2018) Radial-Artery or Saphenous-Vein Grafts in Coronary-Artery Bypass Surgery. N Engl J Med 378(22): 2069-2077.

5. Cheng A, Slaughter MS (2013) How I choose conduits and configure grafts for my patients-rationales and practices. Ann Cardiothorac Surg 2(4): 527-532.

6. Lee MK, Song JY, Kim TY, Kim JH, Choi JB, et al. (2016) Simple Anastomotic Techniques for Coronary Artery Bypass Surgery in Patients with Small Coronary Arteries or a Marked Size Discrepancy Between the Coronary Artery and Graft. Korean J Thorac Cardiovasc Surg 49(6): 485-488.

7. Schreiber C, Augustin N, Bauernschmitt R, Lange R (2002) Modified Bypass Procedure and Apicoaortic Conduit. Herz [Internet] 27(8): 795798.

8. Lopes RD, Mehta RH, Hafley GE, Williams JB, Mack MJ, et al. (2012) Relationship between vein graft failure and subsequent clinical outcomes after coronary artery bypass surgery. Circulation 125(6): 749-756.

9. Otsuka F, Yahagi K, Sakakura K, Virmani R (2013) Why is the mammary artery so special and what protects it from atherosclerosis? Ann Cardiothorac Surg 2(4): 519-526.

10. Taggart DP, Benedetto U, Gerry S, Altman DG, Gray AM, et al. (2019) Bilateral versus Single Internal-Thoracic-Artery Grafts at 10 Years. N Engl J Med 380(5): 437-446.

11. Weiss AJ, Zhao S, Tian DH, Taggart DP, Yan TD (2013) A meta-analysis comparing bilateral internal mammary artery with left internal

\section{ISSN: 2574-1241}

DOI: 10.26717/BJSTR.2019.15.002776

Amer Harky. Biomed J Sci \& Tech Res

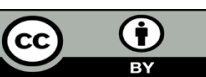

This work is licensed under Creative

Commons Attribution 4.0 License

Submission Link: https://biomedres.us/submit-manuscript.php mammary artery for coronary artery bypass grafting. Ann Cardiothorac Surg 2(4): 390-400.

12. Yi G, Shine B, Rehman SM, Altman DG, Taggart DP (2014) Effect of Bilateral Internal Mammary Artery Grafts on Long-Term Survival. Circulation [Internet] 130(7): 539-545.

13. Gaudino M, Benedetto U, Fremes S, Biondi Zoccai G, Puskas JD, et al. (2018) Radial-Artery or Saphenous-Vein Grafts in Coronary-Artery Bypass Surgery. N Engl J Med 378(22): 2069-2077.

14. Hayward PA, Buxton BF (2013) Mid-term results of the Radial Artery Patency and Clinical Outcomes randomized trial. Ann Cardiothorac Surg 2(4): 458-466.

15. Goldman S, Sethi GK, Holman W, Thai H, Mc Falls E, et al. (2011) Radial Artery Grafts vs Saphenous Vein Grafts in Coronary Artery Bypass Surgery. JAMA 305(2): 167-174.

16. Collins P, Webb CM, Chong CF, Moat NE (2008) Radial Artery Versus Saphenous Vein Patency (RSVP) Trial Investigators. Radial Artery Versus Saphenous Vein Patency Randomized Trial. Circulation 117(22): 28592264.

17. Zhang H, Wang ZW, Wu HB, Hu XP, Zhou Z, et al. (2014) Radial artery graft vs. saphenous vein graft for coronary artery bypass surgery: which conduit offers better efficacy? Herz 39(4): 458-465.

18. Dai C, Lu Z, Zhu H, Xue S, Lian F (2013) Bilateral Internal Mammary Artery Grafting and Risk of Sternal Wound Infection: Evidence from Observational Studies. Ann Thorac Surg 95(6): 1938-1945.

19. Puskas JD, Sadiq A, Vassiliades TA, Kilgo PD, Lattouf OM (2012) Bilateral internal thoracic artery grafting is associated with significantly improved long-term survival, even among diabetic patients. Ann Thorac Surg 94(3): 710-705.

20. Harky A, Balmforth D, Shipolini A, Uppal R (2017) Is endoscopic long saphenous vein harvesting equivalent to open harvesting technique in terms of graft patency? Interact Cardiovasc Thorac Surg 25(2): 323-326.

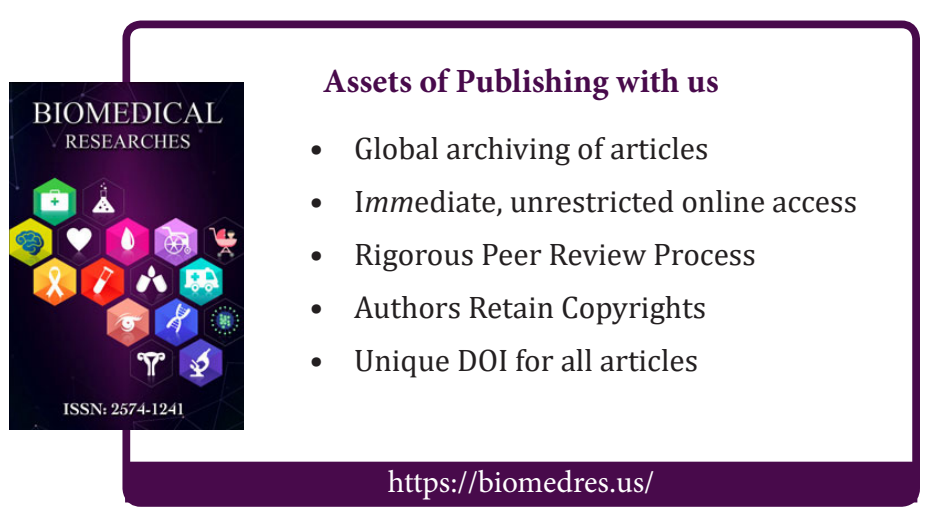

